\title{
Modelling birefringence in isolated elliptical core photonic crystal fibers
}

\author{
Nielsen, Martin Dybendal; Vienne, Guillaume; Jensen, Jacob Riis; Bjarklev, Anders Overgaard
}

Published in:

Proceedings on The 14th Annual Meeting of the IEEE Lasers and Electro-Optics Society

Link to article, DOI:

10.1109/LEOS.2001.969010

Publication date:

2001

Document Version

Publisher's PDF, also known as Version of record

Link back to DTU Orbit

Citation (APA):

Nielsen, M. D., Vienne, G., Jensen, J. R., \& Bjarklev, A. O. (2001). Modelling birefringence in isolated elliptical core photonic crystal fibers. In Proceedings on The 14th Annual Meeting of the IEEE Lasers and Electro-Optics Society (Vol. 2, pp. 707-708). IEEE. https://doi.org/10.1109/LEOS.2001.969010

\section{General rights}

Copyright and moral rights for the publications made accessible in the public portal are retained by the authors and/or other copyright owners and it is a condition of accessing publications that users recognise and abide by the legal requirements associated with these rights.

- Users may download and print one copy of any publication from the public portal for the purpose of private study or research.

- You may not further distribute the material or use it for any profit-making activity or commercial gain

- You may freely distribute the URL identifying the publication in the public portal 
ThG4

9:30am-9:45am

\title{
Modelling Birefringence in Isolated Elliptical Core Photonic Crystal Fibers
}

\author{
Martin Dybendal Nielsen ${ }^{2}$, Guillaume Vienne ${ }^{1}$, Jacob Riis Jensen ${ }^{1}$, Anders Bjarklev \\ ${ }^{1}$ Crystal Fibre A/S \\ ${ }^{2}$ Research Center COM \\ Blokken 84, DK-3460 Birkerød, Denmark \\ Phone: +4543482800 . Fax: +4543482801 , \\ wiww. crustal-fibre.com \\ Technical University of Denmark, DTU, Building 345v, DK-2800 \\ Kgs. Lyngby, Denmark \\ Phone: +45 45426352, Fax: + 4545936581 , \\ www.com.dtu.dk
}

\begin{abstract}
Introduction
In recent years, there has been a significant interest in microstructured optical fibers also referred to as photonic crystal fibers (PCFs). PCFs are optical fibers that employ a microstructured arrangement of low-index material in a background material of higher refractive index. This gives rise to very different wavelength dependencies than what is known from bulk material and the resulting remarkable properties have been extensively described in literature $[1,2]$. The possibility for designing highly birefringent PCFs by employing a non-circular core design has previously been reported $[3,4]$. In small core fibers designed for high non-linearities, the core tends to be very isolated - a fact that has been exploited for simple modelling of optical properties by simply ignoring the cladding region and considering only the core suspended in air [5]. In this work we present simple modelling of birefringence in a fiber with an isolated core having a noncircular cross section. We approximate it with a rod in air having an elliptical cross section. Birefringence values in the order of $10^{-2}$ are reported and compared with both full structural simulations and measurements carried out on a real fiber. These values are significantly larger than what is known from polarization maintaining standard fibers such as Bow Tie and Panda Fibers. Here the typical values are in the order of $10^{-4}[6]$.
\end{abstract}

\section{Results}

The established model considers a dielectric material, invariant in one dimension, with an elliptical cross section, and surrounded by air. Hence, the only parameters are the refractive index of the rod and the major- and minor axis of the ellipsoid, $D_{1}$ and $D_{2}$. Calculation of the supported modes was performed using a full vectorial mode solver. In the calculations $D_{1}$ is kept constant and serves as a fundamental length scale whereas $D_{2}$ is varied to realize different eccentricities, $\varepsilon=D_{2} / D_{1}$. In Figure 1 , the difference in effective index for the two fundamental modes is plotted as function of normalized wavelength for a range of eccentricities. The dotted section of the curves represents the wavelength region in which the fiber only supports the two fundamental modes. This is important to keep in mind since the birefringence value only makes sense in the case where only the fundamental modes are present.

For each value of the eccentricity, the birefringence is seen to have a maximum value that moves towards shorter wavelengths as the core becomes more elliptical. Furthermore, the cutoff wavelength is positioned below the peak value for all considered eccentricities. Very high birefringence values are observed, also in regions that are realistic from a PCF design point of view. For instance, an eccentricity of 0.8 will result in birefringence values in the order of $10^{-2}$ for normalized wavelengths around 1.

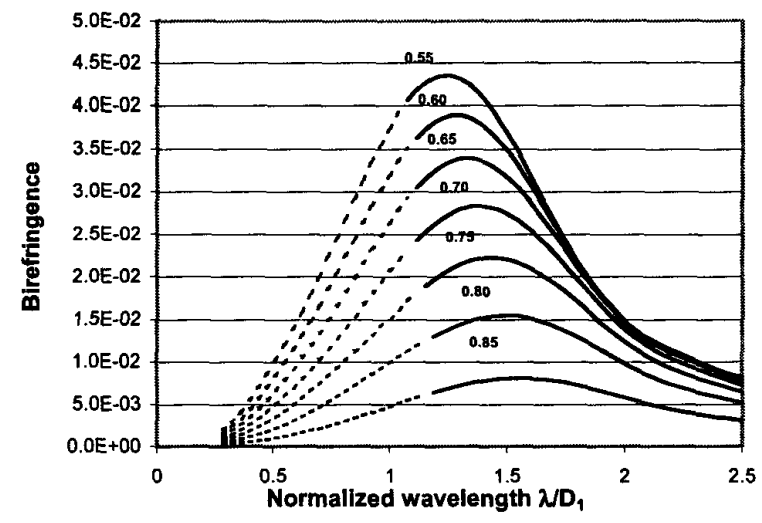

Figure 1 - Calculated birefringence as function of wavelength normalized with respect to the major axis of the core. The value over each curve indicates the eccentricity ranging from 0.55 to 0.85 . The dotted regions on the curves indicate that more than the two fundamental modes are supported. 
Figure 2 shows a Scanning Electron Microscope (SEM) picture of the core region of a PCF having an approximately elliptical core region. The air-filling fraction in the region around the core is high and the core is only connected to the rest of the structure through thin silica bridges, much thinner than the order of near IR wavelengths, and is therefore a reasonable model example.

As shown on the SEM, the core was fitted with an ellipsoid having an area approximately equal to that of the real fiber core. The fitted ellipsoid had a major- and a minor axis of $2.15 \mu \mathrm{m}$ and $1.53 \mu \mathrm{m}$ respectively, yielding an eccentricity of 0.71 . A birefringence calculation using the simple model was then performed along with a simulation based on the SEM picture from figure 2. This simulation employs the exact SEM picture as a super cell without further approximation. The results from both of these calculations are plotted in figure 3 as function of wavelength and good agreement is clearly observed. At wavelengths above a few $\mu \mathrm{m}$, the SEM simulation becomes increasingly inaccurate due to the limited size of the applied super cell.

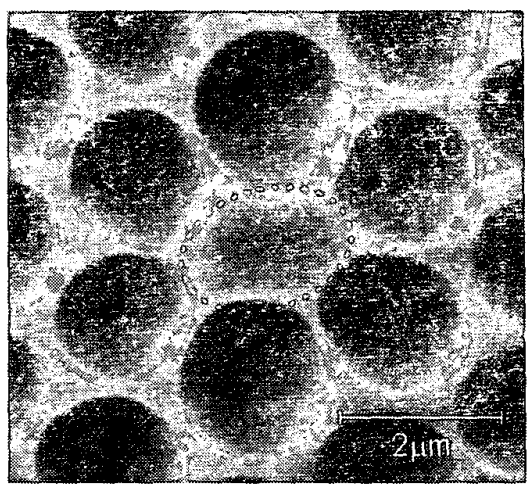

Figure 2 - SEM picture of fiber core of highly birefringent, highly non-linear $P C F$. The fiber and the SEM were kindly provided by Crystal-fibre $A / S$ and Oliver Kuhn from IONAS A/S respectively.
Along with the calculated curves shown in figure 3 , a set of measured data points is plotted. These measured birefringence values are obtained from measurement of the beat length employing two crossed polorizers situated at the input and output end of the PCF, respectively. By transmitting white light through the fiber an oscillating spectrum is obtained with a period directly related to the birefringence and the PCF length. Since the measurements were performed below the cut-off wavelength care was taken to ensure that only the two fundamental modes were excited. The agreement between measured and calculated birefringence values is good and clearly validating the use of the established model.

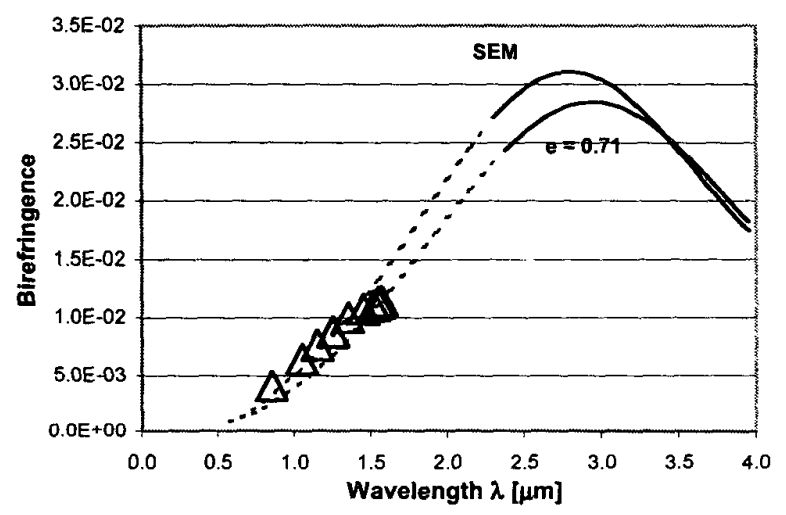

Figure 3 - Comparison of calculations based directly on a SEM picture and from equivalent elliptical fit with an eccentricity of 0.71 . Also plotted is a range of measured data points marked by triangles.

\section{Conclusion}

A simple model for calculation of the birefringence in asymmetric isolated core PCFs employing approximation with an ellipsoid suspended in air is presented. Birefringence values in the order of $10^{-2}$ are obtained and comparison with both calculations based on a SEM picture of a real fiber and measurements performed on the same fiber are presented. In both cases good agreement is observed.

\section{References}

[1] Jes Broeng, Dmitri Mogilevstev, Stig E. Barkou and Anders Bjarklev: "Photonic Crystal Fibers: A New Class of Optical Waveguides", Optical Fiber technology 5, pp. 305-330 (1999).

[2] Jinendra K. Ranka, Roben S. Windeler and Andrew J. Stentz: "Optical properties of high-delta air-silica microstructure optical fibers", Optics Letters, Vol. 25, No. 11, pp. 796-798 (June 2000)

[3] T.P. Hansen, J. Broeng, S.E.B. Libori, E. Knudsen, A. Bjarklev, J.R. Jensen and H. Simonsen: "Highly Birefringent Index-Guiding Photonic Crystal Fibers", IEEE Photonics Technology Letters, Vol. 13, No. 6, pp. 588-590 (June 2001)

[4] Stig Barkou Libori, Jes Broeng, Erik Knudsen, Anders Bjarklev and Harald R. Simonsen: "High-birefringent photonic crystal fiber", OFC 2001 TuM2-1, (March 2001)

[5] J.C. Knight, J. Arriaga, T.A. Birks, A. Ortigosa-Blanch, W.J. Wadsworth and P.St.J. Russel: "Anomalous Dispersion in Photonic Crystal Fiber", IEEE Photonics Technology Letters, Vol. 12, No. 7, pp. 807-809 (July 2000)

[6] Tajima and Sasaki: "Transmission loss of a $125 \mu \mathrm{m}$ diameter PANDA fiber with circular stress-applying parts", Journal of Lightwave Technology., vol. 7, no. 4, pp. 674-679 (April 1989). 